\title{
$\mathrm{BMJ}$
}

\section{WHO guidelines for antimicrobial treatment in children admitted to hospital in an area of intense Plasmodium falciparum transmission: prospective study}

\author{
Behzad Nadjm, clinical lecturer, ${ }^{1}$ Ben Amos, laboratory manager, ${ }^{2}$ George Mtove, clinical research scientist, ${ }^{3}$ \\ Jan Ostermann, associate professor of health economics, ${ }^{4}$ Semkini Chonya, data manager, ${ }^{5}$ Hannah Wangai, \\ research nurse, ${ }^{5}$ Juma Kimera, research laboratory assistant, ${ }^{2}$ Walii Msuya, research clinical officer, ${ }^{2}$ Frank \\ Mtei, data manager, ${ }^{5}$ Denise Dekker, microbiologist, ${ }^{5}$ Rajabu Malahiyo, hospital superintendant, ${ }^{2}$ Raimos \\ Olomi, professor of paediatrics, ${ }^{5}$ John A Crump, associate professor of clinical microbiology, ${ }^{6}$ Christopher J M \\ Whitty, professor of international health, ${ }^{1}$ Hugh Reyburn, clinical senior lecturer ${ }^{1}$
}

London School of Hygiene and Tropical Medicine, London WCIE 7HT

${ }^{2}$ Teule Hospital, Muheza, Tanga, Tanzania

${ }^{3}$ National Institute for Medical Research, Amani Centre, Tanga

${ }^{4}$ Centre for Health Policy, Duke University, Box 90392, Durham, NC 27705, USA

${ }^{5}$ Joint Malaria Programme, Box 2228, Kilimanjaro Christian Medical Centre, Moshi, Tanzania

${ }^{6}$ Division of Infectious Diseases and International Health, Box 102359, Duke University Medical Center, Durham, NC 27710, USA

Correspondence to: H Reyburn Hugh.reyburn@lshtm.ac.uk

Cite this as: BMJ 2010;340:c1350 doi:10.1136/bmj.c1350

\section{ABSTRACT}

Objectives To assess the performance of WHO'S

"Guidelines for care at the first-referral level in developing countries" in an area of intense malaria transmission and identify bacterial infections in children with and without malaria.

Design Prospective study.

Setting District hospital in Muheza, northeast Tanzania.

Participants Children aged 2 months to 13 years admitted to hospital for febrile illness.

Main outcome measures Sensitivity and specificity of WHO guidelines in diagnosing invasive bacterial disease; susceptibility of isolated organisms to recommended antimicrobials.

Results Over one year, 3639 children were enrolled and 184 (5.1\%) died; 2195 (60.3\%) were blood slide positive for Plasmodium falciparum, 341 (9.4\%) had invasive bacterial disease, and 142 (3.9\%) were seropositive for HIV. The prevalence of invasive bacterial disease was lower in slide positive children $(100 / 2195,4.6 \%)$ than in slide negative children $(241 / 1444,16.7 \%)$. Non-typhi Salmonella was the most frequently isolated organism (52/100 (52\%) of organisms in slide positive children and $108 / 241$ (45\%) in slide negative children). Mortality among children with invasive bacterial disease was significantly higher $(58 / 341,17 \%)$ than in children without invasive bacterial disease (126/3298, 3.8\%) ( $P<0.001)$, and this was true regardless of the presence of $P$ falciparum parasitaemia. The sensitivity and specificity of WHO criteria in identifying invasive bacterial disease in slide positive children were $60.0 \%$ (95\% confidence interval $58.0 \%$ to $62.1 \%$ ) and $53.5 \%$ (51.4\% to $55.6 \%$ ), compared with $70.5 \%$ (68.2\% to $72.9 \%)$ and $48.1 \%$ ( $45.6 \%$ to $50.7 \%$ ) in slide negative children. In children with WHO criteria for invasive bacterial disease, only 99/ $211(47 \%)$ of isolated organisms were susceptible to the first recommended antimicrobial agent.

Conclusions In an area exposed to high transmission of malaria, current WHO guidelines failed to identify almost a third of children with invasive bacterial disease, and more than half of the organisms isolated were not susceptible to currently recommended antimicrobials. Improved diagnosis and treatment of invasive bacterial disease are needed to reduce childhood mortality.

\section{INTRODUCTION}

Acute febrile illness is the most common cause of hospital admission and death in African children. ${ }^{1}$ The large majority of these illnesses are due to malaria or invasive bacterial disease, but differentiating between these causes is often difficult and can result in missed diagnoses and inappropriate treatment. ${ }^{2-7}$ Although Plasmodium parasitaemia can be confirmed or excluded by microscopy or rapid diagnostic tests, the diagnosis of invasive bacterial disease is more problematic as blood culture is rarely available and is never in time to guide crucial first treatment decisions. Clinicians therefore often have to rely on the World Health Organization's manual "Management of the child with severe infection or severe malnutrition: guidelines for care at first-referral level in developing countries" (WHO criteria) to guide the presumptive use of anti microbials. $^{8}$

The use of the WHO criteria in an area of moderate transmission of malaria has been shown to identify a high proportion of fatalities due to invasive bacterial disease among children admitted to hospital. ${ }^{9}$ However, the criteria have not so far been systematically assessed in an area of intense transmission of Plasmodium falciparum where infection with Gram negative organisms, especially non-typhi Salmonella, is relatively common and has been associated with severe anaemia, HIV infection, and non-specific clinical features that are not included in the WHO criteria for antimicrobial treatment. ${ }^{3510-14}$ In these areas, which include much of rural Africa, clinicians remain uncertain as to which patients to treat and which antimicrobial to use. 
We report here the results of a one year prospective study of febrile illness in children admitted to a Tanzanian district hospital serving a population exposed to intense $P$ falciparum transmission to assess the ability of the WHO criteria to guide appropriate treatment for invasive bacterial disease.

\section{METHODS}

Study site

This was a one year observational study in Teule Hospital, Muheza, northeast Tanzania, a district hospital serving a rural population of approximately 277000 people with a mortality in children under 5 of 165 per 1000 (Tanzanian census 2002). Transmission of $P$ falciparum is intense (50-700 infected bites/person/year) and perennial, with two seasonal peaks. ${ }^{15}$ The community prevalence of $P$ falciparum in children aged $2-5$ years in the study area was recorded as $88.2 \%$ in $2002 .{ }^{15}$ At the time of the study, routine immunisation did not include vaccination against either Haemophilus influenzae or Streptococcus pneumoniae. HIV seroprevalence among women attending antenatal clinics was $7.2 \%$ in $2007 .{ }^{16}$ In 2002 only $5 \%$ of paediatric admissions were referred for admission from a primary care facility; the remainer were brought directly to the hospital outpatients department by a parent or caregiver.

\section{Eligibility and enrolment}

Consecutive children admitted during the day were given emergency treatment if needed, and then all children were screened for eligibility. Eligible children were aged 2 months to 13 years with a current fever or history of fever within the previous 48 hours. We excluded children with an obvious non-infectious cause for admission such as trauma, surgery, or known malignancy. Children were enrolled over five consecutive days each week. To include children presenting outside normal working hours, we recruited children from Monday to Friday for the first seven months and from Wednesday to Sunday for the next five months. The caregiver of each child in the study gave written informed consent, and pre-test counselling was provided before HIV testing.

\section{Clinical data collection}

After consent procedures, clinical officers (a grade of non-physician clinician in Tanzania) assessed children by using a standard medical history and examination based on the WHO criteria (table 1). ${ }^{817}$ Two study physicians (BN and GM) supervised the collection of clinical data throughout the study. Case management was consistent with WHO guidelines, with the addition that all children with severe malaria were treated with broad spectrum antibiotics consistent with the recommendations of previous studies. ${ }^{18}$ Admission outcomes were recorded at discharge or death.

\section{Blood testing and laboratory procedures}

After cleaning of the skin, venous blood was drawn for culture $(2-5 \mathrm{ml})$, haemoglobin and glucose concentrations (Hemocue, Angelholm, Sweden), serum lactate (Lactate-Pro, Arkray, Kyoto, Japan), HRP-2 based rapid diagnostic test for $P$ falciparum (Paracheck, Orchid Biomedical, Mumbai, India), and a full blood count (Coulter Act/Dif, Beckman-Coulter). We used two rapid tests (Capillus HIV-1, HIV-2 Test, Trinity Biotech, Ireland and Determine HIV-1/2 Test, Abbott Laboratories, IL, USA) in all children to test for HIV antibodies; discordant results were resolved by HIV-1 enzyme linked immunosorbent assay (ELISA) (Vironistika UniForm II Plus-O Test, bioMérieux, NC, USA).${ }^{19}$ Children aged under 18 months with positive

\begin{tabular}{|c|c|c|}
\hline WHO criteria & Recommended antimicrobial & $\begin{array}{l}\text { Chapter, page of guidelines for } \\
\text { care at first referral level } 8\end{array}$ \\
\hline $\begin{array}{l}\text { Sick young infant-any infant aged }<2 \text { months admitted to hospital (not included in this } \\
\text { study) }\end{array}$ & $\begin{array}{l}\text { Ampicillin plus gentamicin IV/IM or penicillin plus } \\
\text { gentamicin IV/IM }\end{array}$ & $6.1,75$ \\
\hline $\begin{array}{l}\text { Meningo-encephalopathy-BCS } 3 \text { or stiff neck or bulging fontanelle or }>2 \text { convulsions in } \\
\text { preceding } 24 \text { hours }\end{array}$ & $\begin{array}{l}\text { Chloramphenicol plus ampicillin IV/IM or } \\
\text { chloramphenicol plus penicillin IV/IM }\end{array}$ & $5.2,62$ \\
\hline $\begin{array}{l}\text { Malaria with shock*_positive slide for malaria plus shock† or BCS }<3 \text { or bulging fontanelle } \\
\text { or }>2 \text { convulsions in preceding } 24 \text { hours }\end{array}$ & Chloramphenicol plus penicillin IV/IM & 5.1.1, 59† \\
\hline $\begin{array}{l}\text { Very severe pneumonia-cough/difficulty breathing plus multiple convulsions or coma or } \\
\text { lethargy or vomiting everything or inability to drink or cyanosis or severe respiratory } \\
\text { distress } \ddagger\end{array}$ & $\begin{array}{l}\text { Chloramphenicol IV/IM or gentamicin plus penicillin } \\
\text { IV/IM§ }\end{array}$ & $3.1 .1,30$ \\
\hline $\begin{array}{l}\text { Severe pneumonia—cough/difficulty breathing plus lower chest indrawing or nasal flaring } \\
\text { or grunting }\end{array}$ & Benzyl penicillin IV/IM & $3.1 .2,32$ \\
\hline Non-severe pneumonia_cough/difficulty breathing plus raised respiratory rate for age & Amoxycillin PO or co-trimoxazole PO & $3.1 .3,32$ \\
\hline $\begin{array}{l}\text { Septicaemia-negative slide for malaria plus axillary temperature } \geq 37.5^{\circ} \mathrm{C} \text { plus inability to } \\
\text { drink/feed or lethargy or }>2 \text { convulsions in preceding } 24 \text { hours or vomiting everything }\end{array}$ & Chloramphenicol plus penicillin IV/IM & $5.4,67$ \\
\hline $\begin{array}{l}\text { Severe acute malnutrition—bilateral oedema or severe wasting or weight for height z-score } \\
<-3\end{array}$ & $\begin{array}{l}\text { Co-trimoxazole PO or amoxycillin plus gentamicinף } \\
\text { IM/IV }\end{array}$ & $7.2 .5,84$ \\
\hline
\end{tabular}

Where categories were used in analysis, children were assigned to one diagnostic category with priority to those higher in list.

$\mathrm{BCS}=\mathrm{B}$ lantyre coma score; IM=intramuscular; $\mathrm{IV}=$ intravenous; $\mathrm{PO}=$ oral.

*"Malaria with shock or signs of meningitis" defined in WHO guidelines ${ }^{8}$; however, children with malaria and signs of meningitis will already be included in category above.

†Shock defined as capillary refill $>3$ seconds or cool peripheries or systolic blood pressure $<50 \mathrm{~mm} \mathrm{Hg}$ (WHO Pocket Book of Hospital Care for Children 6.2.1, 142).

tDefined as oxygen saturation $<90 \%$ or respiratory rate $\geq 70$ breaths/minute.

§Recommended if chloramphenicol is not available.

đRecommended if hypoglycaemia or hypothermia present or if child seems lethargic or "sickly." 


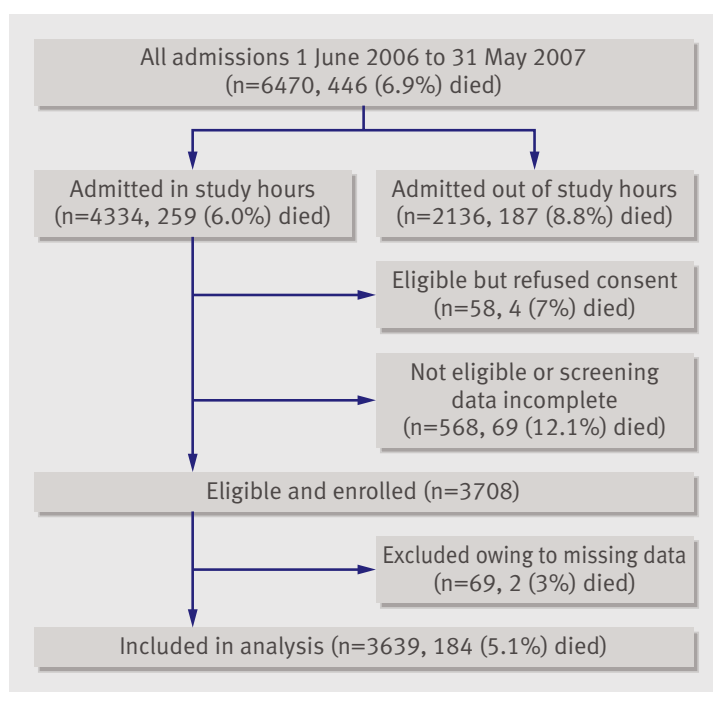

Fig 1 Admissions, deaths, inclusions, and exclusions during study. $2383 / 3639(65.5 \%)$ had an axillary temperature $\geq 37.5$ on admission, $1234 / 3639$ (33.9\%) were afebrile with a history of fever, and $22 / 3639(0.6 \%)$ gave a history of fever with no temperature recorded

results were tested for HIV-1 RNA (Abbott Real-Time m2000 System, Abbott Molecular, IL, USA).

Giemsa-stained blood slides were prepared from venous blood and independently double read; discordant results (either positive/negative discordance or greater than twofold density difference above 400 parasites $/ \mu \mathrm{l}$ ) were resolved by an independent third reading. We calculated parasite densities from the geometric mean of the two closest counts of asexual parasites/200 white blood cells and the actual white blood count or, if missing, 8000 cells/ $\mu$ l. We classified children negative for $P$ falciparum on microscopy and with a positive rapid diagnostic test as "recent malaria" because of the persistence of detectable HRP-2 for up to one month after clearance of parasites. ${ }^{3}$

Blood for culture was inoculated into a BactALERT Paediatric-fan bottle (bioMérieux, France) and incubated in the BacT/ALERT 3D automated microbial detection system. We used standard methods to identify cultures that flagged positive. We determined antimicrobial resistance patterns by disc diffusion and E-test by using the interpretive criteria of the Clinical Laboratory Standards Institute. ${ }^{20} \mathrm{We}$ considered cultures positive for non-cryptococcal yeasts, coagulase negative Staphylococcus, Micrococcus, Corynebacterium, Bacillus sp, or viridans group Streptococci to be contaminants and classified them as "negative culture" unless a pathogenic organism was also isolated. We considered the following as indications for lumbar puncture, regardless of malaria test result: history of multiple or partial seizures, history of seizures in children aged under 6 months or over 6 years, confusion or reduction in conscious level, bulging fontanelle, or neck stiffness. We examined cerebrospinal fluid by microscopy and cultured it. Bacterial identifications were independently confirmed for Salmonella (Queensland Health Forensic and Scientific Services, Brisbane, Australia), Strep pneumoniae, or Haemophilus influenzae b isolates (Netspear, Kilifi, Kenya). The laboratory participated in a bacteriology external quality assurance programme coordinated by a reference laboratory in Moshi, Tanzania, which participates successfully in external quality assurance programmes of the College of American Pathologists and is monitored regularly by the US National Institutes of Health and its contractors.

\section{Data management and analysis}

We used the Cardiff Teleform system (Cardiff, Vista, CA, USA) to scan data into a Microsoft Access database and analysed them in Stata-10. We calculated nutritional $\mathrm{z}$ scores from NCHS/WHO reference data in Epi-6 (CDC, Atlanta, USA). We used the $\chi^{2}$ test to compare proportions.

Table 1 shows the WHO criteria for antimicrobial treatment used in the analysis; these are consistent with the pocket book version of the guideline produced in $2005 .{ }^{821}$ The guideline has been interpreted to apply irrespective of $P$ falciparum parasitaemia; this is consistent with a previous study and justified by the finding that $P$ falciparum parasitaemia is common in asymptomatic children. ${ }^{9152223}$ We used logistic regression models to determine bivariable and multivariable

Table 2 | Sensitivity and specificity of WHO "guidelines for care at first-referral level" criteria for antimicrobial treatment in identifying children with invasive bacterial disease (IBD) by rapid diagnostic test (RDT) and blood slide results

\begin{tabular}{|c|c|c|c|c|c|c|c|c|}
\hline & $\begin{array}{c}\text { Total cases (No; } \\
\text { \% died) }\end{array}$ & No (\%) with IBD & Sensitivity-\% $(95 \% \mathrm{Cl})$ & Specificity-\% $(95 \% \mathrm{Cl})$ & PPV (\%) & NPV (\%) & NNT* & $\begin{array}{c}\% \text { fatal cases with IBD } \\
\text { treated } \dagger\end{array}$ \\
\hline RDT and slide negativef & $943(56 ; 5.9)$ & $143(15.2)$ & 72.7 (69.9 to 75.6$)$ & $47.3(44.1$ to 50.4$)$ & 19.8 & 90.6 & 5.1 & 88.9 \\
\hline $\begin{array}{l}\text { RDT positive, slide } \\
\text { negative§ }\end{array}$ & $501(33 ; 6.6)$ & $98(19.6)$ & $67.3(63.2$ to 71.5$)$ & $49.9(45.5$ to 54.3$)$ & 24.6 & 86.3 & 4.1 & 83.3 \\
\hline Slide positive $<5000 / \mu \mathrm{l}$ & $405(19 ; 4.7)$ & $33(8.1)$ & $60.6(55.9$ to 65.4$)$ & 51.9 (47.0 to 56.8$)$ & 10.1 & 93.7 & 10.1 & 80.0 \\
\hline $\begin{array}{l}\text { Slide positive } 5000-50 \\
000 / \mu \mathrm{l}\end{array}$ & $917(33 ; 3.6)$ & $31(3.4)$ & 67.7 (64.7 to 70.8$)$ & $55.9(52.7$ to 59.1$)$ & 5.1 & 98.0 & 19.6 & 66.7 \\
\hline Slide positive $>50000 / \mu \mathrm{l}$ & $873(43 ; 4.9)$ & $36(4.1)$ & $52.8(49.5$ to 56.1$)$ & $51.6(48.3$ to 54.9$)$ & 4.5 & 96.2 & 22.3 & 60.0 \\
\hline
\end{tabular}

$\mathrm{NPV}=$ negative predictive value; $\mathrm{PPV}=$ positive predictive value.

*Number needed to treat presumptively with antimicrobials to correctly treat one child with IBD.

†Proportion of all IBD associated fatalities with "guidelines for care at first-referral level" indication for antimicrobial treatment.

$\$ 56$ children were RDT negative and blood slide positive and are included in slide positive data (sensitivity of RDT compared with slide reading was $97.4 \%$ ).

$\S$ Assumed to indicate recent infection with $P$ falciparum. 


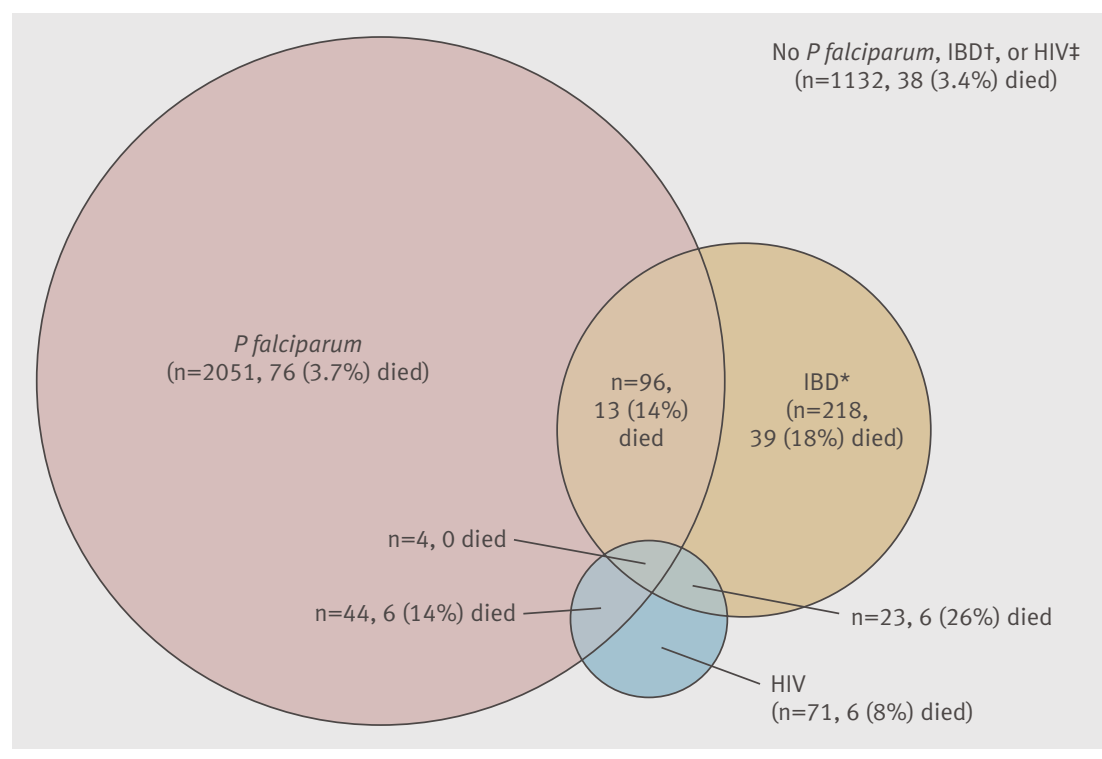

Fig 2 Numbers and deaths of children infected with $P$ falciparum by blood slide, invasive bacterial disease (IBD), or HIV. Areas in Venn diagram approximately to scale. *IBD consisted of 336 children with a positive blood culture, of whom 20 also had a positive cerebrospinal fluid (CSF) culture, and an additional five with a pathogenic organism isolated from CSF and a negative or contaminated blood culture. †Blood cultures classified as negative included 251 $(6.9 \%)$ from which contaminant organisms only were cultured. $\ddagger$ Three negative HIV results were based on Capillus testing only (negative predictive value $99.5 \%$, detail not shown); all other HIV results were based on at least two concordant test results

associations of invasive bacterial disease with WHO criteria, HIV infection, fever, severe anaemia, hypoglycaemia, prostration, raised blood lactate, and recent or current malaria.

\section{RESULTS}

During the one year of the study (June 2006 to May 2007) 6470 children were admitted; 4334 (67\%) were screened for inclusion; 3708 of these were eligible and enrolled, of whom 3639 had sufficient data for analysis (fig 1). The median age of children in the study was 1.6 years; $1054(29.0 \%)$ were aged $2-11$ months, 2273 $(62.5 \%)$ were aged $12-59$ months, and $312(8.6 \%)$ were aged $5-13$ years.
Figure 2 summarises the prevalence of and mortality associated with invasive bacterial disease, $P$ falciparum by blood slide, and HIV. Invasive bacterial disease was identified in $341(9.4 \%)$ of 3639 cases and in 58 (32\%) of 184 deaths. Non-typhi Salmonella was the most frequently isolated bacterial pathogen, accounting for 52 $(52 \%)$ of 100 organisms in slide positive children and $108(45 \%)$ of 241 in slide negative children. Mortality among children with invasive bacterial disease (58/ $341,17 \%$ ) was significantly higher than that in children without invasive bacterial disease (126/3298, 3.8\%) $(\mathrm{P}<0.001)$, and this was true regardless of the presence of $P$ falciparum parasitaemia. The median duration of admission was one day for fatal admissions and three days for non-fatal admissions.

\section{Performance of WHO criteria to target antimicrobial treatment}

Overall, the sensitivity of the WHO criteria to detect invasive bacterial disease was $67.4 \%$ (95\% confidence interval $65.9 \%$ to $69.0 \%$ ), with a specificity of $51.5 \%$ (49.9\% to $53.1 \%)$. Sensitivity was higher among slide negative children $(70.5 \%, 68.2 \%$ to $72.9 \%)$ than among slide positive children $(60.0 \%, 58.0 \%$ to $62.1 \%)$, and specificity was slightly higher among slide positive children $(53.5 \%, 51.4 \%$ to $55.6 \%)$ than among slide negative children $(48.1 \%, 45.6 \%$ to $50.7 \%)$. The sensitivity of the WHO criteria declined with increasing $P$ falciparum parasite density $\left(\mathrm{P}<0.05, \chi^{2}\right.$ test for trend); among children with more than 50000 parasites/ $\mu$, only $19 / 36(53 \%, 50 \%$ to $56 \%)$ children with invasive bacterial disease were correctly identified (table 2).

WHO criteria were significantly more sensitive in identifying invasive bacterial disease associated fatalities $(82.8 \%, 77.3 \%$ to $88.2 \%)$ than non-fatal invasive bacterial disease $(64.3 \%, 62.7 \%$ to $65.9 \%)$, yet 10 $(17 \%)$ of 58 deaths among children with invasive bacterial disease remained unidentified by WHO criteria as needing antimicrobials.

Table 3 shows the prevalence of infecting organisms by WHO criteria of syndromic diagnosis. More than three quarters $(96 / 120,80 \%)$ of children with Gram

Table $3 \mid$ Number (\%) of children with and without one of WHO indications for antimicrobial treatment by organism isolated from blood or cerebrospinal fluid

\begin{tabular}{|c|c|c|c|c|c|c|c|}
\hline Guidelines indication & $\begin{array}{l}\text { Non-typhi } \\
\text { Salmonella }\end{array}$ & $\begin{array}{l}\text { Haemophilus } \\
\text { influenzae b }\end{array}$ & $\begin{array}{c}\text { Other Gram } \\
\text { negative* }\end{array}$ & $\begin{array}{c}\text { Strep } \\
\text { pneumoniae }\end{array}$ & $\begin{array}{c}\text { Other Gram } \\
\text { positive }\end{array}$ & $\begin{array}{l}\text { No organism } \\
\text { isolated }\end{array}$ & Total \\
\hline Meningo-encephalopathy & 7 (3) & $18(7)$ & $5(2)$ & $5(2)$ & $4(2)$ & $216(85)$ & 255 \\
\hline Malaria with shock & $4(5)$ & 0 & $2(2)$ & 0 & 0 & $76(93)$ & 82 \\
\hline Very severe pneumonia & $31(8)$ & $6(2)$ & $10(3)$ & $15(4)$ & $5(3)$ & $311(82)$ & 378 \\
\hline Severe pneumonia & $13(7)$ & $5(3)$ & $2(1)$ & $9(5)$ & $1(5)$ & $171(85)$ & 201 \\
\hline Non-severe pneumonia & $39(5)$ & $4(1)$ & $15(2)$ & $15(2)$ & $6(1)$ & $766(91)$ & 845 \\
\hline Septicaemia & $1(4)$ & 0 & $1(4)$ & $1(4)$ & 0 & $25(89)$ & 28 \\
\hline Severe acute malnutrition & $2(5)$ & $1(3)$ & $2(5)$ & $1(3)$ & 0 & $34(85)$ & 40 \\
\hline No WHO indication $\ddagger$ & $63(3.5)$ & $5(0.3)$ & $24(1.3)$ & $10(0.6)$ & $9(0.5)$ & 1699 (93.9) & 1810 \\
\hline
\end{tabular}

One child in whom Strep pneumoniae was isolated from cerebrospinal fluid and non-typhi Salmonella was isolated from blood was classified as infected with Strep pneumoniae alone.

*Included 23 E coli and 11 Salmonella typhi.

†Included 17 Staph aureus.

$\$ 225 / 1810(12.4 \%)$ of children who did not meet an existing WHO indication for antimicrobial treatment had severe anaemia (haemoglobin $<5 \mathrm{~g} / \mathrm{dl}$ ). 
positive or $H$ influenzae infections presented with clinical features that met one of the WHO criteria, whereas just over half $(134 / 221,61 \%)$ of children with non- $H$ influenzae Gram negative infections met one of these criteria $(\mathrm{P}<0.001)$. Non- $H$ influenzae Gram negative infections accounted for more than three quarters $(151 / 198,76 \%)$ of organisms isolated in children with recent or current malaria but less than half $(70 / 143$, $49 \%$ ) of organisms isolated from children who were both slide negative and rapid diagnostic test negative $(\mathrm{P}<0.001)$ (fig 3).

Risk factors for invasive bacterial disease

We assessed clinical and laboratory features associated with invasive bacterial disease by using bivariate odds ratios and a multivariable logistic regression model (table 4). After control for the presence of any WHO criteria, HIV infection, and current or recent malaria, a significant association remained between invasive bacterial disease and axillary temperature above $38^{\circ} \mathrm{C}$, severe anaemia (haemoglobin $<5 \mathrm{~g} / \mathrm{dl}$ ), and hypoglycaemia (blood sugar $<2.5 \mathrm{mmol} / \mathrm{l}$ ) (table 4). Prostration was also associated with increased odds of invasive bacterial disease among children without current or recent malaria (odds ratio $2.54,95 \%$ confidence interval 1.37 to $4.70, \mathrm{P}=0.003)$.

\section{Additions to WHO criteria to improve sensitivity}

To evaluate potential candidates for addition to the WHO criteria, we identified factors from those associated with invasive bacterial disease (table 4). We

Table 4 | Logistic regression model of factors associated with invasive bacterial disease in all children in study

\begin{tabular}{|c|c|c|}
\hline Factors & Unadjusted odds ratio $(95 \% \mathrm{Cl})$ & Adjusted odds ratio $(95 \% \mathrm{Cl})$ \\
\hline WHO criteria & $2.20(1.74 \text { to } 2.79)^{\star \star}$ & $1.67(1.28 \text { to } 2.17)^{\star \star}$ \\
\hline Meningo-encephalopathy & $1.84(1.28 \text { to } 2.64)^{\star \star *}$ & \\
\hline Malaria with shock & $0.59(0.34$ to 1.00$)$ & \\
\hline Very severe pneumonia & $2.16(1.67 \text { to } 2.81)^{\star \star}$ & \\
\hline Severe pneumonia & $1.85(1.25 \text { to } 2.74)^{\star \star}$ & \\
\hline Non-severe pneumonia & 0.98 (0.75 to 1.28$)$ & \\
\hline Septicaemia & $5.58(3.92 \text { to } 7.96)^{\star \star}$ & \\
\hline Severe acute malnutrition & $1.72(0.72$ to 4.13$)$ & \\
\hline HIV positive & $2.38(1.54 \text { to } 3.68)^{\star \star}$ & 1.47 (0.91 to 2.35$)$ \\
\hline Axillary temperature $>38^{\circ} \mathrm{C}$ & $1.34(1.07 \text { to } 1.67)^{\star}$ & $1.44(1.13 \text { to } 1.84)^{\star \star}$ \\
\hline Prostration† & $1.42(1.03 \text { to } 1.95)^{\star}$ & 1.01 (0.65 to 1.55$)$ \\
\hline Shock & 1.14 (0.69 to 1.88$)$ & $0.90(0.50$ to 1.60$)$ \\
\hline Haemoglobin $<5 \mathrm{~g} / \mathrm{dl}$ & $1.43(1.08 \text { to } 1.89)^{\star}$ & $1.56(1.13 \text { to } 2.14)^{\star \star}$ \\
\hline Glucose $<2.5 \mathrm{mmol} / \mathrm{l}$ & $2.33(1.44 \text { to } 3.75)^{\star \star}$ & $2.46(1.39 \text { to } 4.35)^{\star \star}$ \\
\hline Lactate $>5 \mathrm{mmol} / \mathrm{l}$ & $1.46(1.07 \text { to } 1.99)^{\star}$ & \\
\hline Slide positive & $0.24(0.19 \text { to } 0.30)^{\star \star}$ & \\
\hline RDT positive, slide negativef & $2.90(2.24 \text { to } 3.75)^{\star \star}$ & $1.29(0.95$ to 1.75$)$ \\
\hline Slide positive $<5000 / \mu \mathrm{l}$ & 0.84 (0.58 to 1.23$)$ & $0.55(0.36 \text { to } 0.84)^{\star \star}$ \\
\hline Slide positive $5000-50000 / \mu \mathrm{l}$ & $0.27(0.19 \text { to } 0.40)^{\star \star}$ & $0.20(0.13 \text { to } 0.31)^{\star \star}$ \\
\hline Slide positive $>50000 / \mu \mathrm{l}$ & $0.35(0.24 \text { to } 0.50)^{\star \star}$ & $0.24(0.16 \text { to } 0.37)^{\star \star}$ \\
\hline \multicolumn{3}{|c|}{$\begin{array}{l}\text { RDT=rapid diagnostic test. } \\
\text { *P }<0.05 \text {. } \\
\star * \text { P }<0.001 \text {. } \\
\text { †Inability to sit unsupported or, if age }<8 \text { months, inability to drink. } \\
\text { †RDT positive and slide negative assumed to indicate recent infection with } P \text { falciparum. }\end{array}$} \\
\hline
\end{tabular}

Fig 3 | Proportion of organisms isolated from children with invasive bacterial disease by $P$ falciparum infection status. RDT=rapid diagnostic test

added HIV first on the assumption that this would be incorporated if WHO guidelines included care of children with HIV in the "Fever" chapter. The further criteria of "severe anaemia $(\mathrm{Hb}<5 \mathrm{~g} / \mathrm{dl})$," "prostration," and "current fever $>38^{\circ} \mathrm{C}$ " increased the sensitivity of the WHO criteria to $86.2 \%(85.1 \%$ to $87.3 \%)$, with a specificity of $24.8 \%$ (23.4\% to $26.2 \%)$. Table 5 shows these results by malaria slide results.

In slide positive children, the prevalence of invasive bacterial disease was $60 / 1035(5.8 \%)$ if one of the WHO criteria was present compared with 26/679 $(3.8 \%)$ if none was present but the child had any of severe anaemia, prostration, HIV infection, or "current fever $>38^{\circ} \mathrm{C}$." This contrasts with slide negative children, among whom the prevalence of invasive bacterial disease was $170 / 794(21.4 \%)$ if one of the WHO criteria was present compared with $38 / 265$ (14\%) if none was present but the child had any of severe anaemia, prostration, HIV infection, or current fever $>38^{\circ}$ C. Hypoglycaemia, although strongly associated with invasive bacterial disease, applied to only 22 children with such disease; all but three of these already met WHO criteria, and all but two of them met one of the criteria classified as D in table 5 .

\section{Antimicrobial susceptibility}

In children with invasive bacterial disease, the isolated organism was susceptible in vitro to the WHO recommended antibiotic in $33 \%$ to $100 \%$ of cases, with a weighted mean of 99/211 (47\%). Co-trimoxazole for non-severe pneumonia and parenteral penicillin for severe pneumonia were associated with the lowest in vitro susceptibilities (32\% and 33\%) (table 6). Table 7 shows susceptibilities of common isolates to routinely available antibiotics.

\section{DISCUSSION}

Our findings show that, in a typical district hospital serving a population exposed to intense transmission 
of $P$ falciparum, WHO criteria for antimicrobial treatment failed to identify almost a third of children who had definite invasive bacterial disease. Among those who were identified by WHO criteria, the isolated organism was not susceptible to the first recommended antimicrobial drug in more than half the cases.

As expected, invasive bacterial disease was more likely in slide negative children than in slide positive children. In these co-infected children, however, invasive bacterial disease was not confined to those with low density infections that are often found incidentally in African children; a third of the invasive bacterial disease- $P$ falciparum co-infections occurred in children with high density infections that are highly unlikely to be due to incidental parasitaemia. ${ }^{22}$ This finding is consistent with those of Berkley et al, who have recently quantified the association of high density malaria infection and bacterial disease. ${ }^{24}$ In addition, we found that invasive bacterial disease was associated with high mortality irrespective of $P$ falciparum infection, highlighting the importance of considering invasive bacterial disease in children admitted to hospital irrespective of whether a malaria slide is positive. The failure of the WHO criteria to identify many of these children was to a large extent due to the high prevalence of non-typhi Salmonella infection and its association with severe anaemia and other non-specific clinical features that are not currently included in the WHO criteria. ${ }^{8}$ The introduction of pneumococcal and $\mathrm{Hib}$ vaccines in many African countries in the next one to two years is likely to make these infections relatively more important.

Our results are consistent with increasing evidence that malaria is a risk factor for non-typhi Salmonella and some other Gram negative infections. ${ }^{12425}$ Reasons for this are still unclear but may relate to increased vulnerability to non-typhi Salmonella infection associated with haemolysis, as the association also applies in children with sickle cell disease and in animals with experimentally induced haemolysis. ${ }^{2627}$ The association of non-typhi Salmonella with "recent malaria" that we and one previous study have observed suggests that malaria may result in relatively prolonged increased vulnerability to bacterial infection, especially by enteric organisms. ${ }^{3}$

\section{Validity and generalisability of findings}

Although no study can automatically be generalised to other settings, our findings are similar to those of Berkley et al, who found that in an area of moderate $P$ falciparum transmission the WHO criteria correctly identified $66 \%$ of invasive bacterial disease in slide positive children and $76 \%$ in slide negative children (after the exclusion of "sick young infants," a group at high risk of invasive bacterial disease who are all recommended for antimicrobial treatment by these guidelines). ${ }^{9}$ These figures are only slightly higher than our estimates; the difference may be due to a higher proportion of non-typhi Salmonella infections in our study.

The diagnostic performance of the WHO criteria is likely to vary with local epidemiology, especially in relation to bacterial disease and malaria, but the consistency of our findings with several others in identifying non-typhi Salmonella and other Gram negative infections as leading causes of bacteraemia in African children suggest that our findings are likely to apply widely. ${ }^{11^{1428-33}}$ In addition, the low level of antimicrobial susceptibility that we found is also consistent with others. ${ }^{103234-36}$ The association between malaria and bacterial disease identified in our study is consistent with several other studies and was slightly weaker than found by Berkley et al. ${ }^{18}$ Similarly, the association of increased mortality with bacterial disease is similar to that found in several other studies, ${ }^{1837}$ although a study in Malawi did not find an association between mortality and bacterial disease among children with severe malaria admitted to a paediatric intensive care unit. $^{11}$

Table $\mathbf{5}$ |Sensitivity, specificity, and predictive values of selected additions to WHO "guidelines for care at first-referral level" criteria for presumptive treatment of invasive bacterial disease (IBD) by presence or absence of $P$ falciparum parasitaemia

\begin{tabular}{|c|c|c|c|c|c|c|}
\hline & $\begin{array}{l}\text { Sensitivity-\% } \\
(95 \% \mathrm{Cl})\end{array}$ & $\begin{array}{l}\text { Specificity-\% } \\
(95 \% \mathrm{Cl})\end{array}$ & PPV (\%) & NPV (\%) & NNT* & $\begin{array}{c}\% \text { fatal cases with } \\
\text { IBD treated } \dagger\end{array}$ \\
\hline \multicolumn{7}{|l|}{ Blood slide positive for $P$ falciparum } \\
\hline A-guidelines criteria & $60.0(58.0$ to 62.1$)$ & $53.5(51.4$ to 55.6$)$ & 5.8 & 96.6 & 17.3 & 69.2 \\
\hline $\mathrm{B}-\mathrm{A}$ or HIV & $62.0(60.0$ to 64.0$)$ & $52.5(50.4$ to 54.6$)$ & 5.9 & 96.7 & 17.1 & 69.2 \\
\hline $\mathrm{C}-\mathrm{B}$ or severe anaemia & $68.0(66.1$ to 70.0$)$ & $45.3(43.2$ to 47.4$)$ & 5.6 & 96.7 & 17.9 & 84.6 \\
\hline D-C or prostration & $72.0(70.1$ to 73.9$)$ & $43.4(41.4$ to 45.5$)$ & 5.7 & 97.0 & 17.5 & 92.3 \\
\hline E-D or axillary temperature $338^{\circ} \mathrm{C}$ & $86.0(84.6$ to 87.5$)$ & $22.3(20.6$ to 24.0$)$ & 5.0 & 97.1 & 19.9 & 92.3 \\
\hline \multicolumn{7}{|l|}{ Blood slide negative for $P$ falciparum } \\
\hline A-guidelines criteria & $70.5(68.2$ to 72.9$)$ & $48.1(45.6$ to 50.7$)$ & 21.4 & 89.1 & 4.7 & 86.7 \\
\hline $\mathrm{B}-\mathrm{A}$ or HIV & $71.4(69.0$ to 73.7$)$ & 46.6 (44.1 to 49.2$)$ & 21.1 & 89.0 & 4.7 & 86.7 \\
\hline $\mathrm{C}-\mathrm{B}$ or severe anaemia & $75.5(73.3$ to 77.7$)$ & $42.4(39.9$ to 44.9$)$ & 20.8 & 89.6 & 4.8 & 88.9 \\
\hline D-C or prostration & $75.9(73.7$ to 78.1$)$ & $42.0(39.4$ to 44.5$)$ & 20.8 & 89.7 & 4.8 & 91.1 \\
\hline E-D or axillary temperature $338^{\circ} \mathrm{C}$ & $86.3(84.5$ to 88.1$)$ & $29.3(26.9$ to 31.6$)$ & 19.6 & 91.4 & 5.1 & 93.3 \\
\hline
\end{tabular}

$\mathrm{NPV}=$ negative predictive value; $\mathrm{PPV}=$ positive predictive value.

*Number needed to treat presumptively with antimicrobials to correctly treat one child with IBD.

†Proportion of all IBD associated fatalities identified for antimicrobial treatment. 
Table 6 |Proportion (\%) of bacterial isolates susceptible in vitro to recommended and other commonly available antimicrobials by WHO "guidelines for care at first-referral level" criteria for antimicrobial treatment*

\begin{tabular}{|c|c|c|c|c|c|c|c|c|c|c|c|}
\hline & Amp/chlor & Pen/chlor & Chlor & Pen/gent $†$ & Pen & Amoxy & Co-trimox & Amp/gent $†$ & Ceftriaxone & Pen/cipro & Azithromycin \\
\hline $\begin{array}{l}\text { Meningo- } \\
\text { encephalopathy }\end{array}$ & $22 / 34(65) \ddagger$ & $19 / 34(56)$ & $16 / 32(50)$ & $22 / 24(92)$ & $5 / 38(13)$ & $13 / 34(38)$ & $6 / 25(24)$ & $28 / 29(97)$ & $31 / 31(100)$ & $12 / 13(92)$ & 26/29 (90) \\
\hline Malaria with shock & $2 / 6(33)$ & $2 / 6(33) \ddagger$ & $2 / 6(33)$ & $4 / 5(80)$ & $0 / 6(0)$ & $2 / 6(33)$ & $3 / 5(60)$ & $4 / 5(80)$ & $5 / 6(83)$ & $5 / 5(100)$ & $3 / 8(38)$ \\
\hline Very severe pneumonia & $32 / 62(52)$ & $31 / 63(49)$ & $26 / 62(42) \ddagger$ & $54 / 60(90)$ & $16 / 65(25)$ & $26 / 62(42)$ & $17 / 58(29)$ & $55 / 60(92)$ & 60/61 (98) & $53 / 53(100)$ & $38 / 55(69)$ \\
\hline Severe pneumonia & $20 / 29(69)$ & $19 / 30(63)$ & $17 / 29(59)$ & $29 / 29(100)$ & 10/30 (33)‡ & $18 / 29(62)$ & $9 / 26(35)$ & $29 / 29(100)$ & $30 / 30(100)$ & $23 / 23(100)$ & $27 / 35(77)$ \\
\hline Non-severe pneumonia & $38 / 69(55)$ & $36 / 69(52)$ & $30 / 66(46)$ & $63 / 72(88)$ & $16 / 76(21)$ & $32 / 71(45) \ddagger$ & $21 / 66(32)$ & 63/72 (88) & 71/72 (996) & $67 / 67(100)$ & $57 / 86(66)$ \\
\hline Septicaemia & $1 / 2(50)$ & $1 / 2(50) \ddagger$ & $1 / 2(50)$ & $3 / 3(100)$ & $1 / 3(33)$ & $1 / 2(50)$ & $1 / 2(50)$ & $3 / 3(100)$ & $2 / 2(100)$ & $3 / 3(100)$ & $4 / 5(75)$ \\
\hline Severe acute & $5 / 6(83)$ & $5 / 6(83)$ & $5 / 6(83)$ & $5 / 5(100)$ & $1 / 6(17)$ & 4/6 (67) & $3 / 5(60)$ & 6/6 (100)‡ & $6 / 6(100)$ & $5 / 5(100)$ & $3 / 5(60)$ \\
\hline
\end{tabular}

malnutri

Amoxy=amoxicillin; amp=ampicillin; chlor=chloramphenicol; co-trimox=co-trimoxazole; cipro=ciprofloxacin; gent=gentamicin; pen=penicillin .

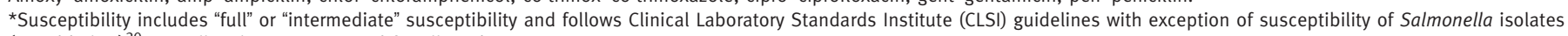
(noted below) ${ }^{20}$; not all isolates were tested for all antibiotics.

†Salmonella susceptibilities to gentamicin are shown as actual in vitro results, although CLSI guidelines recommend that for clinical practice all Salmonella should be reported as "not susceptible" owing to poor intracellular penetration of gentamicin.

fFirst recommendation treatment.

A limitation of our study was our inability to enrol children at night; case fatality was higher in children admitted outside study hours, probably because "out of hours" admissions are more severely ill and possibly because initial clinical management is of lower quality at these times. ${ }^{38}$ Mortality was also high in children who were excluded from the study because of missing data (often because they died soon after admission), and our findings are thus likely to underestimate mortality in children whose need for antimicrobials was not recognised by WHO criteria. However, children who die soon after admission probably present too late to benefit from antimicrobial treatment.

\section{WHO guidelines}

We evaluated the WHO manual "Management of the child with severe infection or severe malnutrition: guidelines for care at first-referral level," 8 as this is the standard WHO guide for paediatric inpatient care and has been adopted as policy by the ministries of health of many resource poor countries. A WHO guideline for treatment of malaria (2006) also exists; it proposes a "low threshold" for the use of antimicrobials in children with severe malaria to treat Salmonella infections in particular. ${ }^{17}$ The existence of separate clinical guidelines for malaria and general paediatric care is an unfortunate consequence of the vertical approach to malaria. Possibly as a result of this, antimicrobial treatment is not mentioned in the Tanzanian or Kenyan national guidelines for the treatment of severe malaria.

\section{Additional indications for antimicrobials in children}

Among children in this study, the addition of "severe anaemia" and "prostration" to current indications resulted in a significant improvement in the detection of invasive bacterial disease in both fatal and non-fatal cases. This is consistent with several studies that have shown an association between severe anaemia and invasive bacterial disease. ${ }^{112939}$ "Current fever" has previously been associated with invasive bacterial disease, ${ }^{40}$ and its inclusion as a criterion for antimicrobials resulted in a gain in sensitivity, although this was at the expense of a substantial drop in specificity. However, even in children with malaria, application of these more inclusive criteria resulted in fewer than 20 children qualifying for presumptive antimicrobial treatment to correctly identify one child with invasive bacterial disease, a figure that compares favourably with policies that recommend presumptive treatment of non-severe malaria. ${ }^{17}$ Given the increase in mortality associated with invasive bacterial disease, this seems a reasonable proposition; however, a need exists for a more formal economic evaluation that includes such factors as the financial cost of newer

Table 7|Proportion (\%) of bacterial isolates susceptible in vitro to commonly available antimicrobials

\begin{tabular}{lcccc} 
& Penicillin/amoxicillin & Chloramphenicol & Co-trimoxazole & Gentamicin \\
Non-typhi Salmonella & $49 / 148(33)$ & $53 / 153(35)$ & $49 / 145(34)$ & $147 / 152(97) \dagger$ \\
\hline Strep pneumoniae & $51 / 51(100)$ & $41 / 48(85)$ & $22 / 45(49)$ & - \\
\hline Haemophilus influenzae & $12 / 38(32)$ & $16 / 38(42)$ & $2 / 28(7)$ & $22 / 23(96)$ \\
\hline E coli & $2 / 21(10)$ & $5 / 18(28)$ & $1 / 20(5)$ & $9 / 20(45)$ \\
\hline Staph aureus & $1 / 15(7)$ & $11 / 13(85)$ & $10 / 14(71)$ & $13 / 16(81)$
\end{tabular}

Susceptibility includes "full" or "intermediate" susceptibility and follows Clinical Laboratory Standards Institute (CLSI) guidelines with exception of susceptibility of Salmonella isolates (noted below). ${ }^{20}$

*Salmonella isolates were multi-resistant (resistant to amoxicillin, chloramphenicol, and co-trimoxazole) in 85/141 (60.3\%) cases.

†Salmonella susceptibilities to gentamicin are shown as actual in vitro results, although CLSI guidelines recommend that for clinical practice all

Salmonella should be reported as "not susceptible" owing to poor intracellular penetration of gentamicin. 


\section{WHAT IS KNOWN ON THIS TOPIC}

Presumptive diagnosis of malaria is common in children admitted to hospital in Africa and is associated with failure to provide treatment for bacterial disease

Invasive bacterial disease is a major cause of mortality in African children, alone and in association with malaria

Overlapping clinical features create difficulties in distinguishing between invasive bacterial disease and malaria in African children

\section{WHAT THIS STUDY ADDS}

In a malaria endemic area, almost a third of the children with definite invasive bacterial disease were not identified by WHO criteria for the presumptive use of antimicrobials

The high prevalence of non-typhi Salmonella and other Gram negative infections may contribute to the poor performance of the WHO guidelines in this setting

More than half of the isolates from children in a malaria endemic area were not susceptible to the WHO recommended antimicrobial

antimicrobials and the selection of resistance that may result from their wider use.

For routine care, the high mortality associated with invasive bacterial disease, the low sensitivity of a single blood culture, ${ }^{4142}$ the poor quality of routine slide results, and the apparently strong bias of hospital clinicians towards the diagnosis of malaria all suggest that inclusive rather than restrictive indications for presumptive antimicrobial treatment are needed to ensure more effective treatment for children admitted to hospitals in resource poor settings. ${ }^{6344}$

\section{Choice of antimicrobials}

Our results, which are consistent with those of other studies, show that commonly used antimicrobials often lack activity against the Gram negative organisms that are often the most common cause of bacterial infection in African children. ${ }^{103234-36}$ In our study, two thirds of the organisms identified in children who met the $\mathrm{WHO}$ criteria for severe pneumonia were resistant to penicillin (the first recommended antimicrobial) and more than a third were resistant to chloramphenicol or ampicillin (which might be used as an alternative). Our in vitro estimate of susceptibility to gentamicin is likely to overestimate its in vivo efficacy as, although some extracellular effect against salmonellas can be expected, salmonella is a largely intracellular organism and the limited penetration of gentamicin is likely to limit its effect. ${ }^{456}$ As a consequence, gentamicin is not usually recommended for treatment of invasive salmonellosis. ${ }^{20}$

The choice of antimicrobials in resource poor settings is obviously constrained by cost and availability. However, as recently highlighted by Graham and English, ${ }^{47}$ the high incidence and fatality of non-typhi Salmonella bacteraemia in Africa, which is often resistant to commonly used antimicrobials, constitutes a serious and neglected public health challenge. Better evidence to guide antimicrobial choices is needed, but current evidence suggests that in malaria endemic areas of Africa ciprofloxacin (not usually available parenterally) plus penicillin or ceftriaxone alone are the leading candidates for first choice antimicrobials in severely ill children.

\section{Clinical trials of antibiotic indications in sick children}

Our results raise questions that ideally should be informed by the results of a randomised clinical trial of clinical indications for the use of antibiotics. However, such a trial would need to be large. According to the data from our study and an assumption that antimicrobials in children with severe malarial anaemia and no WHO indication for antimicrobials would reduce their mortality by $50 \%$ (although a much smaller reduction would still be worthwhile), 2670 children would need to be randomised from more than 17000 children with severe malaria. In addition, ethical concerns could exist about randomising severely anaemic children to a "no antimicrobial" arm given the strength of current evidence. ${ }^{112939} \mathrm{WHO}$ and others need to reach a consensus on this question; if a clinical trial is feasible and ethical, it should be set up with urgency. If not, existing evidence should be used to help to modify current guidelines for the treatment of children with invasive bacterial disease in malaria endemic areas.

\section{Conclusions}

The WHO criteria for presumptive antimicrobial treatment have poor sensitivity in children living in this area endemic for $P$ falciparum in Africa, and the guidelines should be re-examined. This study shows that simple and available clinical criteria may significantly increase detection of invasive bacterial disease in severe and fatal illness in African children. Currently recommended antimicrobials often lack activity against common bacterial infections in Africa, and more effective diagnosis and treatment of bacterial disease in resource poor settings are urgently needed.

We thank the staff and patients of Teule Hospital for their cooperation during the study. Aikande Shoo, Halima Mohammed, Charles Mgaya, Selina Wycliffe, Emmanuel Swai, Edward Mtili, Christina Kemi, Stella Emmanuel, Rosalia Marwa, and Simphorosa Silaye were involved in clinical and laboratory data collection. Anne B Morrissey and Susan C Morpeth provided advice and support for microbiology. Contributors: BN was responsible for all the clinical data collection, contributed to the data analysis, and wrote the manuscript with HR. BA, $\mathrm{DD}$, and JK were responsible for the laboratory analysis, drafted section of the methods and provided critical review of the manuscript. GM was responsible for clinical data collection and contributed to the writing of the manuscript. J0 was responsible for the statistical analysis and provided critical review of the manuscript. KC and FM were responsible for managing the data and provided critical review of the manuscript. HM WM, and RM were responsible for clinical data collection and provided critical review of the manuscript. RO, JAC, and CJMW contributed to funding applications, study design, and critical review of the manuscript. HR was responsible for the study design, obtained core funding, co-wrote the manuscript, and contributed to the analysis; he is the guarantor. Funding: Core funding for the study was provided by European Commission (Europaid) grant code SANTE/2004/078-607. BN was supported by grants from the Berkeley Fellowship, Sir Halley Stewart Trust, and Pfizer Pharmaceuticals. Pfizer Pharmaceuticals provided equipment and consumables for microbiology. Abbott Pharmaceuticals provided reagents for HIV testing. Netspear (www.netspear.org) funded the E-tests, which were performed at the KEMRI/Wellcome Trust Centre for Geographic Medicine (Coast), Kilifi, Kenya. None of the funders had a role in the design, analysis, or interpretation of results. Competing interests: None declared. 
Ethical approval: The study was approved by the ethics committees of the National Institute for Medical Research, Tanzania, and the London School of Hygiene and Tropical Medicine. Written informed consent was obtained from the caregiver of each child in the study, and pre-test counselling was provided before HIV testing.

Data sharing: Technical appendix, statistical code, and dataset are available from the corresponding author (hugh.reyburn@lshtm.ac.uk) Specific consent for data sharing was not obtained prospectively from study participants but may be granted by the Tanzanian national ethical review board.

1 Bryce J, Boschi-Pinto C, Shibuya K, Black RE. WHO estimates of the causes of death in children. Lancet 2005;365:1147-52.

2 Berkley JA, Mwangi I, Mellington F, Mwarumba S, Marsh K. Cerebral malaria versus bacterial meningitis in children with impaired consciousness. OJM 1999;92:151-7.

3 Brent AJ, Oundo JO, Mwangi I, Ochola L, Lowe B, Berkley JA. Salmonella bacteremia in Kenyan children. Pediatr Infect Dis J 2006;25:230-6.

4 English M, Punt J, Mwangi I, McHugh K, Marsh K. Clinical overlap between malaria and severe pneumonia in African children in hospital. Trans R Soc Trop Med Hyg 1996;90:658-62.

5 Evans JA, Adusei A, Timmann C, May J, Mack D, Agbenyega T, et al. High mortality of infant bacteraemia clinically indistinguishable from severe malaria. QJM 2004;97:591-7.

6 Reyburn H, Mbatia R, Drakeley C, Carneiro I, Mwakasungula E, Mwerinde 0 , et al. Overdiagnosis of malaria in patients with severe febrile illness in Tanzania: a prospective study. BMJ 2004;329:1212

7 Reyburn H, Mwakasungula E, Chonya S, Mtei F, Bygbjerg I, Poulsen A, et al. Clinical assessment and treatment in paediatric wards in the north-east of the United Republic of Tanzania. Bull World Health Organ 2008;86:132-9.

8 World Health Organization. Management of the child with a serious infection or severe malnutrition: guidelines for care at the firstreferral level in developing countries. WHO, 2000.

9 Berkley JA, Maitland K, Mwangi I, Ngetsa C, Mwarumba S, Lowe BS, et al. Use of clinical syndromes to target antibiotic prescribing in seriously ill children in malaria endemic area: observational study. BMJ 2005;330:995.

10 Sigauque B, Roca A, Mandomando I, Morais L, Quinto L, Sacarlal J, et al. Community-acquired bacteremia among children admitted to rural hospital in Mozambique. Pediatr Infect Dis / 2009;28:108-13.

11 Bronzan RN, Taylor TE, Mwenechanya J, Tembo M, Kayira K Bwanaisa L, et al. Bacteremia in Malawian children with severe malaria: prevalence, etiology, HIV coinfection, and outcome. J Infect Dis 2007; 195:895-904.

12 Graham SM, Hart CA, Molyneux EM, Walsh AL, Molyneux ME. Malaria and Salmonella infections: cause or coincidence? Trans R Soc Trop Med Hyg 2000;94:227.

13 Graham SM, Walsh AL, Molyneux EM, Phiri Al, Molyneux ME. Clinical presentation of non-typhoidal Salmonella bacteraemia in Malawian children. Trans R Soc Trop Med Hyg 2000;94:310-4.

14 Walsh AL, Phiri AJ, Graham SM, Molyneux EM, Molyneux ME. Bacteremia in febrile Malawian children: clinical and microbiologic features. Pediatr Infect Dis / 2000;19:312-8.

15 Maxwell CA, Chambo W, Mwaimu M, Magogo F, Carneiro IA, Curtis CF. Variation of malaria transmission and morbidity with altitude in Tanzania and with introduction of alphacypermethrin treated nets. Malar / 2003:2:28.

16 Edmonds S, Shangalawe L, Meadway J. Getting pregnant women on to HAART (highly active antiretroviral therapy): developing a strategy for advanced prevention of mother-to-child transmission of HIV (PMTCT+) in rural Tanzania. HIV Med 2009;10(suppl 1):26S.

17 World Health Organization. Guidelines for the treatment of malaria. WHO, 2006

18 Berkley J, Mwarumba S, Bramham K, Lowe B, Marsh K. Bacteraemia complicating severe malaria in children. Trans R Soc Trop Med Hyg 1999;93:283-6.

19 Mayhood MK, Afwamba IA, Odhiambo CO, Ndanu E, Thielman NM, Morrissey $\mathrm{AB}$, et al. Validation, performance under field conditions, and cost-effectiveness of Capillus HIV-1/HIV-2 and determine HIV-1/ 2 rapid human immunodeficiency virus antibody assays using sequential and parallel testing algorithms in Tanzania. / Clin Microbiol 2008;46:3946-51.

20 Clinical and Laboratory Standards Institute. Performance standards for antimicrobial susceptibility testing; nineteenth informational supplement. M100-S19, Vol 29, No 3, 2009.

21 World Health Organization. Pocket book of hospital care for children guidelines for the management of common illnesses with limited resources. WHO, 2005.

22 Chandler Cl, Drakeley C], Reyburn H, Carneiro I. The effect of altitude on parasite density case definitions for malaria in northeastern Tanzania. Trop Med Int Health 2006;11:1178-84.

23 Smith T, Schellenberg JA, Hayes R. Attributable fraction estimates and case definitions for malaria in endemic areas. Stat Med 1994;13:2345-58.
24 Berkley JA, Bejon P, Mwangi T, Gwer S, Maitland K, Williams TN, et al. HIV infection, malnutrition, and invasive bacterial infection among children with severe malaria. Clin Infect Dis 2009:49:336-43.

25 Mabey DC, Brown A, Greenwood BM. Plasmodium falciparum malaria and Salmonella infections in Gambian children.J Infect Dis 1987;155:1319-21.

26 Onwubalili JK. Sickle cell disease and infection. J Infect 1983;7:2-20.

27 Roux CM, Butler BP, Chau JY, Paixao TA, Cheung KW, Santos RL, et al. Both hemolytic anemia and malaria parasite-specific factors increase susceptibility to non-typhoidal Salmonella infection in mice. Infect Immun 2010; published online 25 January.

28 Archibald LK, Kazembe PN, Nwanyanwu O, Mwansambo C, Reller LB, Jarvis WR. Epidemiology of bloodstream infections in a bacille Calmette-Guerin-vaccinated pediatric population in Malawi. / Infect Dis 2003;188:202-8.

29 Bahwere P, Levy J, Hennart P, Donnen P, Lomoyo W, Dramaix-Wilmet $M$, et al. Community-acquired bacteremia among hospitalized children in rural central Africa. Int I Infect Dis 2001;5:180-8

30 Shaw AV, Reddy EA, Crump JA. Etiology of community-acquired bloodstream infections in Africa. 46th annual meeting of the Infectious Diseases Society of America. Infectious Diseases Society of America, 2008.

31 Berkley JA, Lowe BS, Mwangi I, Williams T, Bauni E, Mwarumba S, et al. Bacteremia among children admitted to a rural hospital in Kenya. N Engl/ Med 2005;352:39-47.

32 Blomberg B, Manji KP, Urassa WK, Tamim BS, Mwakagile DS, Jureen R, et al. Antimicrobial resistance predicts death in Tanzanian children with bloodstream infections: a prospective cohort study. BMC Infect Dis 2007;7:43.

33 Lepage P, Bogaerts J, Van Goethem C, Ntahorutaba M, Nsengumuremyi F, Hitimana DG, et al. Community-acquired bacteraemia in African children. Lancet 1987:1:1458-61.

34 Bejon P, Mwangi I, Ngetsa C, Mwarumba S, Berkley JA, Lowe BS, et al. Invasive Gram-negative bacilli are frequently resistant to standard antibiotics for children admitted to hospital in Kilifi, Kenya. J Antimicrob Chemother 2005;56:232-5.

35 Gordon MA, Graham SM, Walsh AL, Wilson L, Phiri A, Molyneux E, et al. Epidemics of invasive Salmonella enterica serovar enteritidis and $S$ enterica serovar typhimurium infection associated with multidrug resistance among adults and children in Malawi. Clin Infect Dis 2008;46:963-9.

36 Scott JA, Mwarumba S, Ngetsa C, Njenga S, Lowe BS, Slack MP, et al. Progressive increase in antimicrobial resistance among invasive isolates of Haemophilus influenzae obtained from children admitted to a hospital in Kilifi, Kenya, from 1994 to 2002. Antimicrob Agents Chemother 2005;49:3021-4.

37 Bassat Q, Guinovart C, Sigauque B, Mandomando I, Aide P, Sacarlal J, et al. Severe malaria and concomitant bacteraemia in children admitted to a rural Mozambican hospital. Trop Med Int Health 2009;14:1011-9.

38 Berkley JA, Brent A, Mwangi I, English M, Maitland K, Marsh K, et al. Mortality among Kenyan children admitted to a rural district hospital on weekends as compared with weekdays. Pediatrics 2004:114:1737-8.

39 Calis JC, Phiri KS, Faragher EB, Brabin BJ, Bates I, Cuevas LE, et al. Severe anemia in Malawian children. $N$ Engl I Med 2008:358:888-99.

40 Brent AJ, Ahmed I, Ndiritu M, Lewa P, Ngetsa C, Lowe B, et al. Incidence of clinically significant bacteraemia in children who present to hospital in Kenya: community-based observational study. Lancet 2006;367:482-8.

41 Cockerill FR 3rd, Wilson JW, Vetter EA, Goodman KM, Torgerson CA, Harmsen WS, et al. Optimal testing parameters for blood cultures. Clin Infect Dis 2004;38:1724-30.

42 Lee A, Mirrett S, Reller LB, Weinstein MP. Detection of bloodstream infections in adults: how many blood cultures are needed? J Clin Microbiol 2007;45:3546-8

43 Chandler Cl, Jones C, Boniface G Juma K, Reyburn H, Whitty Cl. Guidelines and mindlines: why do clinical staff over-diagnose malaria in Tanzania? A qualitative study. Malar / 2008;7:53.

44 Reyburn H, Mbakilwa H, Mwangi R, Mwerinde O, Olomi R, Drakeley C, et al. Rapid diagnostic tests compared with malaria microscopy for guiding outpatient treatment of febrile illness in Tanzania: randomised trial. BMJ 2007;334:403.

45 Fierer J, Hatlen L, Lin JP, Estrella D, Mihalko P, Yau-Young A. Successful treatment using gentamicin liposomes of Salmonella dublin infections in mice. Antimicrob Agents Chemother 1990;34:343-8

46 Kihlstrom E, Andaker L. Inability of gentamicin and fosfomycin to eliminate intracellular Enterobacteriaceae. I Antimicrob Chemother 1985;15:723-8

47 Graham SM, English M. Non-typhoidal salmonellae: a management challenge for children with community-acquired invasive disease in tropical African countries. Lancet 2009:373:267-9.

Accepted: 25 January 2010 